\title{
Migraine in neurological department of fann teaching hospital in Dakar
}

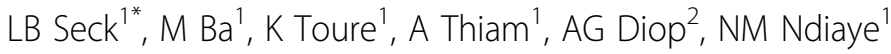 \\ From The European Headache and Migraine Trust International Congress \\ London, UK. 20-23 September 2012
}

\section{Introduction}

Migraine is the most frequent primary headache, one of the main complaint of our neurological out-patients department, but it has not been studied enough in our structure.

\section{Purpose}

We aimed to assess clinical features of migraine in a sub-saharian teaching hospital.

\section{Methods}

We carried out a prospective study in the out-patient department of the neurological service of Fann teaching hospital, in Dakar.

\section{Results}

One hundred patients were collected, aged from 9 to 64 years with sex-ratio 5.25. It was migraine without aura in $83 \%$ of patients and with aura in $17 \%$. Triggering factors were mainly psychical, climatic, hormonal, food, fatigue, physical effort, sensorial. The pain was hemicranial in $73 \%$, throbbing in $82 \%$, tightening or itching in $18 \%$. Headache duration varied from 4 to 72 hours in $75 \%$, less than 4 hours in $10 \%$, more than 72 hours in $15 \%$. Pain intensity was mild for $2 \%$, moderate for $49 \%$ and severe for $49 \%$. It occured once a day to less than once a month. Photophobia was found in $78 \%$, nausea in $48 \%$, vomiting in $33 \%$. Aura was visual, psychical or sensorial. All patients benefited from treatment of acute pain, while $83 \%$ underwent permanent treatment in addition. Fifty eight per cent of women who had already been pregnant reported improvment during pregnancy.Of yhe whole sample, $59 \%$ had never seen a doctor for their migraine, using self-treatment or not pain-killer at all. Fifty three per cent of patients experienced a good outcome, while it was sationary for $31 \%, 17 \%$ being lost sight.

\section{Conclusion}

Even if it is less studied in Africa, and is supposed to be less frequent in black people [1], migraine keeps its classical features. It considerably alter quality of life $[2,3]$ but yet tend to be neglected by patients who do not care enough about it [3].

\section{Author details}

${ }^{1}$ Neurological Department - Fann Teaching Hospital, Senegal. ${ }^{2}$ Neurological Department - Fann Teaching Hospital, Senegal.

Published: 21 February 2013

References

1. Dent W, Spiss H, Helbok R, Matuja W, Scheunemann S, Schmutzhard E: Prevalence of migraine in a rural area in South Tanzania: a door-to-door survey. Cephalalgia 2004, 24(11):960-966.

2. Moriarty-Sheehan M: Migraine and its treatment with $5-\mathrm{HT} 1 \mathrm{~B} / 1 \mathrm{D}$ agonists (triptans). J Am Acad Nurse Pract 2002, 14(8):354-9, quiz 360-362.

3. Lawrence EC: Diagnosis and management of migraine headaches. South Med J 2004, 97(11):1069-1077.

doi:10.1186/1129-2377-14-S1-P107

Cite this article as: Seck et al:: Migraine in neurological department of fann teaching hospital in Dakar. The Journal of Headache and Pain 2013 14(Suppl 1):P107. 